\title{
Perspectivas da alteridade na obra de Luciano de Samósata
}

\author{
Jacyntho Lins Brandão \\ Universidade Federal de Minas Gerais
}

\begin{abstract}
LINS BRANDÃO, J. Perspectivas de alteridade na obra de Luciano de Samósata. Classica, Belo Horizonte, 3:119-128, 1990.
\end{abstract}

RESUMẼ: L'ouvre de Lucien a posé souvent des problèmes difficiles à resoudre. Depuis Croiset, qui affirme qu'elle n'a point d'unité, les opinions diffèrent: de l'interprétation de Helm à la théorie de la mimésis de Bompaire ou la lecture sociale de Baldwin. Je me propose de la lire dans le cadre d'une "poétique de l'alterité", dans le contexte des problèmes d'identité que soulèvent les rapports des barbares hellénisés avec la tradition grecque.

É preciso, antes de tudo, confessar que ainda se sabe pouco sobre Luciano, sobre sua obra e sobre seu tempo, o que faz com que qualquer tentativa de compreensão de conjunto de sua produção seja extremamente difícil. Há a opção fácil de admitir, como Croiset (1899:158), que a obra de Luciano não tem nenhuma unidade, ou que constitui apenas um tipo de diversão inconseqüente destinada a um público também inconseqüente, ponto de vista que mesmo um estudo da qualidade do de Bompaire (1958) não descarta totalmente. $\overline{\mathbf{E}}$ espantoso que tais juízos, aplicados a toda literatura da época de Luciano, continuem a ser repetidos em trabalhos recentes, dentre os quais citaria o artigo de van Groningen (1965 : 53-56), texto de conferência proferida durante um evento de primeiro plano como são os Congressos Internacionais da FIEC, no qual se afirma que a literatura do segundo século é, em geral, frágil, sem inspiração, raramente bem direcionada e pautando-se por escolhas equivocadas que tendem a esconder a ausência de vida interior através de um rumoroso clangor de palavras, pois os homens 
do mesmo século são eles também débeis, incapazes de dar mostras de energia psíquica e interiormente pobres. Juizos gratuitos, superficialidade de análise e avalanche de preconceitos - é apenas o que posso extrair de propostas desse teor, em que se mesclam dois tipos de interferências perniciosas: de um lado, o ponto de vista do estudioso moderno, seus (pre) conceitos e sua expectativa com relação à literatura; de outro, o uso da literatura grega até $0 \quad V^{\circ}$ século a. C. como critério para o julgamento da literatura do segundo século d.C.. Não desejo aqui polemizar sobre este ponto, apenas exemplificar como a crítica em geral se perde na abordagem da obra de Luciano e de seus contemporâneos, mesmo que reconheça na primeira qualidades de uso da língua e de estilo, não logrando discernir contudo seu sentido enquanto conjunto.

A classificação vaga e, por isso mesmo, até certo ponto adequada, que etiqueta Luciano como polígrafo, diz tudo e não diz nada sobre sua obra. Polígrafo não é apenas quem escreve muito, mas também quem escreve sobre muitas coisas. Luciano escreveu muito e sobre assuntos muito variados. Sua produção constitui um convite à dispersão e um desafio para a compreensão de conjunto. O problema que levanto diz respeito a essa compreensão de conjunto e se expressa na inquirição do sentido da própria poligrafia, do que faz com que o muito disperso venha a ser conjunto, cuja unidade, pelo menos de um ponto de vista exterior, é resguardada pela autoria única e pelo fato de ter sido conservado e transmitido como o corpus lucianeum. Ora, não é segundo o gênero nem segundo o conteúdo que esse corpus se conforma, estando antes à margem de classificaçes desse teor, marcado justamente pela falta de um gênero fixo e de um conteúdo estável. Essa dificuldade de percepção dos critérios que organizam o corpus lucianeum é que dá margem à classificação de polígrafo, sob a qual se escamoteia o impasse, mas que, ao mesmo tempo, patenteia não só a dificuldade, porém, em certa medida, a impossibilidade de classificação. Um corpus que não é nem retórico, nem épico, nem trágico, nem biográfico, nem filosófico, nem historiográfico, nem mitológico ou religioso, tem sua unidade - ou melhor: sua organicidade — em quê? Devemos admitir que tal corpus não seja um corpo, isto é, que não tenha organicidade? Qual o sentido de um corpo assim agenérico e inclas- 
sificável? - ou, dito de outro modo, de um corpo a que deve corresponder um outro gênero e uma outra classificação fora das correntes? O estatuto de outro não representa, portanto, inicialmente, nenhuma solução, mas a mera constatação do que há de mais tangível no corpus lucianeum. Para ter alguma força de coesão deve entretanto ser testado com relação ao sentido, pois é o sentido que se busca: é na alteridade que está o sentido da obra de Luciano? a alteridade tem nela algum sentido? que sentido tem nela a alteridade? Sem negar a validade de outros enfoques, ${ }^{1}$ essas têm sido as questões que vêm norteando meu processo de reflexão sobre a obra de Luciano, na inquirição sobre se seria justo reconhecer como parte constituinte de sua poética um certo tipo de "retórica da alteridade", nos moldes da que Hartog (1980) identifica em Heródoto.

Tomo o conceito de alteridade do ponto de vista abrangente de um dado relacional, isto é, cuja função decorre de um conjunto de relações: se se admite que algo seja o outro, será sempre o outro de algo. Assim, da perspectiva de um determinado "senso comum" próprio da cultura européia, o corpo é o outro da alma; o escravo, do senhor; a mulher, do homem; a criança, do adulto; o bárbaro, do civilizado; o monstruoso, do bem formado (ou do "formoso" em sentido estrito) ; o louco, do são de espírito; o cômico, do sério; o mentiroso, do verdadeiro; a decadência, do apogeu; a cópia, do modelo. O que perpassa a série, citada propositadamente de modo aleatório, é a admissão de que em algumas entidades se reconhece, social e culturalmente, uma certa identidade que se nega a seu outro. O outro orbita em torno do próprio, interdita-se a ele a plenitude de um estatuto autônomo, ou seja, sua entidade e identidade dependem totalmente daquilo de que ele é outro. Se pois indagamos sobre o sentido da alteridade no corpus lucianeum, é preciso preservar o esquema de relações em que ele se manifesta, o que seria propriamente a história, indagando sobre as perspectivas da alteridade que teria o mundo helenizado do segundo século. Alguns autores negam, com efeito, que se possa constatar, na

Como os de Bompaire 1958; Mc Carthy 1934; Baldwin 1973; Helm 1906; Caster 1938; os quais considero adequados no que se propõem. 
Antigüidade, qualquer noção do outro enquanto outra pessoa (cf. Entralgo 1983), pelo menos nos termos propostos pela filosofia moderna e contemporânea. Deve-se contudo observar que, de um ponto de vista teórico, Platão admite uma categoria definida como tò héteron, a partir da oposição a tò tautón (Timeu 35 a ss.; Teeteto 185 c 9; Sofista 254 e 3; 255 b 3), a tò ón (Sofista $256 \mathrm{~d}-\mathrm{e}$ ) e a tò hén (Parmênides $143 \mathrm{c}$ ss.), enquanto Aristóteles se refere a certas formas de alteridade "física", isto é, natural, nomeadamente a do bárbaro, a do escravo e a da mulher (Pol. I, 2, 1252 b), o que hoje enquadraríamos como categorias de alteridade social. Mesmo que faltassem essas referências diretas nos textos dos filósofos, e ainda que elas não tenham a importância que têm tais questões no pensamento moderno e contemporâneo, creio que se deve antes buscar detectar as situações em que se atribui alguma funcionalidade à categoria do outro, na medida em que o estatuto de certas entidades políticas, sociais e culturais se conforma diante daquilo de que elas são o outro. Parece-me que J.-P. Vernant logra precisar com bastante acuidade o que seria, em geral, o outro para um grego: "o que é outro em relação à criatura viva, ao ser humano (ánthropos), ao civilizado, ao homem adulto (anér), ao grego, ao cidadão" (1985:12), e ainda "o que é absolutamente outro, o indizível, o impensável, o puro caos”, de que ele particularmente se ocupa em $\boldsymbol{A}$ morte nos olhos, estudando a configuração dos deuses gregos relacionados com máscaras.

Diferentes perspectivas de alteridade podem ser descobertas nos textos de Luciano, as quais poderiam ser distribuídas pelos itens referidos. Ressalta, antes de tudo, seu gosto por personagens marginalizadas, como prostitutas, eunucos, escravos, pobres e humildes. Nessa mesma esfera se incluem os filósofos cínicos - Diógenes, Crates e, sobretudo, Menipo - marginais por opção, pintados como autênticos "clochards" ou vagabundos, para usar o termo de Festugière (1977:131). Existe ainda o gosto pelo diferente com relação ao grego, isto é, pelo estrangeiro e bárbaro - englobando citas, etíopes e, de um modo especial, os romanos, antítese mais acabada de tudo aquilo que conforma o modo de vida grego. Também o outro com relação ao vivo, bastando lembrar o gosto pelo contato com os mortos, bem como o outro que escapa à esfera 
terrestre e humana - a chusma de habitantes da lua, das estrelas, do sol, de ilhas perdidas em mares ignotos, etc., além dos deuses. Mais ainda, na esfera dos próprios deuses gregos, constata-se a presença de uma verdadeira multidão de deuses bárbaros que funcionam como contraponto dos primeiros. Outro ponto em que se descobrem dados interessantes diz respeito ao gosto por espaços de alteridade, representados pelo submundo das grandes cidades, bem como por lugares estrangeiros, pelo exótico, por desertos, o mundo dos mortos, os confins da terra, o extraterrestre, as utopias. Em vista da freqüência com que se registra, não teria receio de estabelecer essa opção pelo outro como um dos eixos programáticos da atividade literária de Luciano. Os comentadores que vêem nela apenas um gosto fútil pelo exótico, característico da época, parece-me que se enganam e não atinam com sentido da própria crítica luciânica considerada, pelos mesmos estudiosos, em geral, como negativa e anódina porque não defende nada, só ataca superficialmente. A natureza e a intencionalidade do ataque dependem contudo do entendimento do corpo de oposições em que se efetiva e do efeito que busca.

Não nego que Luciano não seja inovador ao eleger os outros como seus heróis, pois esse interesse pelo diferente acompanha toda a trajetória da cultura grega desde Homero. Luciano tem clara consciência de ser um sucessor do velho poeta ou, mais particularmente, da personagem homérica que, na Odisséia, narra fatos espantosos sobre seres estranhos que habitam terras desconhecidas, o herói Ulisses (cf. Histórias verdadeiras, I, 3). Tem ainda consciência de que, em sua ficção, apenas leva a extremos tendências presentes nos historiadores, sobretudo em Heródoto e Ctésias, e nos filósofos (Hist. verd. I, 2-3) . O que haveria contudo de peculiar em Luciano seria uma mudança de enfoque: não mais o outro traduzido pelo próprio e, assim, feito inteligivel para o grego, mas o próprio posto em juízo a partir do ponto de vista do outro, pelo simples fato de ser contraposto a ele. Assim, afirma no Hermótimo (17), não tem valor quem se louva a si mesmo; a opinião fidedigna deve partir dos outros (álloi), ou seja, a verdade só pode 
surgir quando se rompe a esfera do costumeiro para avaliá-lo de perspectiva diferente, eliminando o risco do erro por ignorância. $\hat{\mathrm{E}}$ o que ilustra o exemplo seguinte:

se um certo etiope, nunca outros (állous) homens tendo visto, como nós somos, por nunca ter saído de seu país, em alguma reunião dos etíopes afirmasse e dissesse não existir em nenhum lugar da terra homens brancos ou amarelos nem outros a não ser negros, acreditariam nele? ou lhe diria algum dos mais velhos dos etiopes: Tu sabes isto de onde, ó temerário? pois nunca saíste de junto de nós nem viste - por Zeus! - como são as coisas junto dos outros (tà parà tô̂s állois). Não pareceria que o mais velho teria retrucado com justeza? (Herm. 31).

Mais que o gosto de citar um exemplo exótico, ou aliado a esse gosto, está a convicção de que o outro vem a ser o critério para o correto e isento julgamento do próprio. O etíope temerário peca por ignorância e presunção, mas pode-se também pecar por declarada parcialidade e não por falta de experiência ou conhecimento, o que a anedota do tirano da Sicília ilustra bem:

Conta-se que Gelão de Siracusa tinha a boca malcheirosa e tal fato foi escondido dele durante muito tempo, pois ninguém ousava advertir um tirano, até uma certa mulher estrangeira (tína gynaîka xénen), tendo dormido com ele, ousar dizer-lhe o que se passava. Ele, voltando para junto de sua própria mulher, encolerizou-se por ela não tê-lo advertido, sendo conhecedora, mais do que ninguém, do mau cheiro. Ela suplicou-lhe que a perdoasse pois, não tendo nunca dormido com outro homem (állou andrós), nem falado de perto, cria que todos os homens exalavam da boca o mesmo hálito. (Herm. 34).

A mulher do tirano, como o etíope, erra por ignorância baseada na falta de experiência, mas os demais súditos calam-se por medo e assim faltam com a verdade, revelada apenas por essa personagem que se move completamente na esfera da alteridade, na condição tríplice de mulher, prostituta e estrangeira. Não se deve perder de vista que os dois exemplos citados aparecem num texto dedicado à discussão das diferentes escolas de filosofia, ou seja, está em 
causa o esforço de pensar criticamente a questão da verdade e não o prazer de contar histórias estranhas e exóticas. Não nego que o segundo elemento exista, mas subordina-se à intenção maior da obra - em que aliás Luciano insiste com frequiência: o discernimento entre o verdadeiro e o falso, o autêntico e o aparente no corpus da produção cultural grega, ou seja, no contexto da rede de representações que a sociedade elabora sobre si mesma.

Existe claramente na obra de Luciano uma tendência em identificar o ponto de vista do outro como o mais verdadeiro porque livre de coações. A própria verdade, ainda no Hermótimo, é definida como um állo ti, algo outro do pseúdesthai (do mentir) de todas as filosofias, assim como a felicidade pode ser állo ti, algo outro do que supõem as filosofias. $\widehat{\mathrm{E}}$ justamente a definição deste állo ti que a maioria dos comentadores cobra de Luciano, acusando-o de exercitar uma crítica puramente destrutiva. Acredito, todavia, que ele indique o que seja állo ti, embora seja algo que não se classifique segundo correntes filosóficas ou religiosas, ou seja, algo que está à margem das classificações correntes e que poderia mais ou menos ser reconhecido como um "senso comum", um "tà koinà phroneîn" (Herm. 72). Tudo o que escapa dessa esfera "não difere em nada dos hipocentauros, das quimeras e das górgonas e de quantas outras coisas (hósa álla) os sonhos, os poetas e os pintores modelam, sendo eles livres, mas que nunca existiram e nunca poderão existir" (Herm. 72) . Assim se reconhece nessas outras coisas, por processo de espelhamento, uma função de desmascaramento de tudo o que foge ao senso comum, sobre a qual se constrói a poética de Luciano, definida como um exercício de denúncia através do riso. Parece-me que Korus (1984) tem razão em ver justamente no senso comum o fundamento sobre o qual se constrói a teoria do humor de Luciano, na medida em que os costumes parecem ridículos apenas para aqueles que não estão familiarizados com certos valores éticos que prejudicam um julgamento isento. Assim, o cita Anácarsis pode rir dos costumes gregos, mas não Sólon. $\overline{\mathbf{E}}$ o riso do bárbaro que tem a capacidade de pôr finalmente à prova o familiar para um grego, de fornecer critério seguro para o discernimento do que realmente tem valor, separando o que seria próprio do senso comum do que é apenas excentricidade (cf. Anácarsis 9 ss.). 
Não interessa a Luciano apenas narrar e descrever costumes estranhos para os gregos, traduzir o modo de vida dos outros em termos gregos. O que lhe interessa no fundo é identificar o que é mais próprio do modo de ser grego, que interfere sempre no texto, ainda que como modelo ausente. Sua poética da alteridade é assim marcada por intenção de discernimento extremamente aguda e exigente. Nesse sentido, ele difere de Homero e de Heródoto e tem consciência disso. Não se trata simplesmente de um grego que vê, com olhos gregos, os outros. Não se trata também, entretanto, de um outro que vê, como olhos estrangeiros, os gregos. A questão da alteridade em Luciano passa pelo estatuto pouco definido do aculturado que, deixando de lado o que lhe é próprio, adota uma outra cultura mas não se sente nunca totalmente adotado por ela. É significativo que nos textos essenciais para a compreensão do sentido da poética de Luciano, quando o autor se defende, se justifica ou reflete sobre sua produção, sistematicamente se encontrem alusões a sua origem bárbara:

"eu sou sírio" - diz ele à Filosofia em Os ressuscitados -
"nascido às margens do Eufrates. Mas que importa?... o
caráter e a ciência não dependem absolutamente do fato
de se ter nascido em Soles, em Chipre, na Babilônia ou
em Estagira e não se vale menos a teus olhos por se ser
bárbaro de língua, desde que se tenha um espírito reto e
justo" (Res. 18).

Se, num plano ideal, Luciano defende esse ponto de vista universalista, experimenta no plano prático as limitações de tal estatuto irresolvido, isto é, o estatuto de outro com relação ao grego, reconhecendo ser "ultrajante habitar no estrangeiro" (Elogio da pátria 8). Todavia, não se entrega a chorar sua sorte, mas deixa entender justamente que é a condição de xénos que lhe garante liberdade de pensamento. Xeniteía e eleuthería se conjugam para formar um ideal de vida intelectual, expresso com relação à função do historiador em particular, mas que pode ser aplicado a todos os escritores em geral (o termo syngrapheuis, com efeito, pode designar tanto um quanto outro) : 
"assim deve ser para mim o syngrapheús: sem medo, incorrupto, livre, amigo da franqueza e da verdade, chamando de figo o figo e de gamela a gamela, como diz o poeta cômico (...) estrangeiro (xénos) nos livros e sem cidade (ápolis), autônomo, sem rei (abasíleutos), não pensando o que achará este ou aquele, mas dizendo os fatos" (Como se deve escrever a história 41).

Ser xénos (estrangeiro, estranho, forasteiro, hóspede), de onde decorre não estar submetido a cidade, lei ou rei, é que cria condições para o exercício da incorruptibilidade, da franqueza e da liberdade (ver Bandinelli 1976). O inverso dessa situação é retratado no opúsculo Sobre os convivas assalariados (que poderíamos também traduzir por "hóspedes assalariados"), em que descreve a ultrajante privação de liberdade a que -são submetidos os intelectuais gregos que, em busca de prestígio e riqueza, ingressam no cortejo dos grandes senhores romanos, desempenhando funções baseadas na bajulação e na compra de favores, insuportáveis para alguém que viveu antes em contato com as Musas (13), ou seja, reduzidos a uma condição de alteridade ultrajante, tratados como objetos que se usam certo tempo e em seguida se descartam. A estes o estatuto do outro é imposto à força pelos senhores a que servem. Luciano, pelo contrário, descobre no estatuto de xénos justamente um ideal que extrapola critérios de organização social, política ou econômica, realizado em espaços marginais - como no caso de Timão no deserto (Timão ou o misantropo), como para os mortos igualados no Hades (Diálogos dos mortos; Descida ao Hades ou o Tirano) - ou em utopias: na cidade perfeita descrita no Hermótimo, todos os que chegam inscrevem-se como cidadãos, classificando-se em uma tribo ou em uma fratria; mas isso só é possível porque, na cidade perfeita, todos os habitantes são xenoi (estrangeiros, hóspedes) vindos de fora; não há um único autóctone e ela está povoada de bárbaros, de escravos, de pobres e de humildes (24); todos aí vivem livres de riqueza, cobiça e outros males semelhantes, no seio de igualdade e de liberdade (22).

A questão da alteridade não se resolve pois pela completa assimilação - que seria antes algo de nefasto, como o que acontece com o assalariado - mas pela idealização do estatuto de xénos. 
De um certo modo, Luciano procede a uma idealização da própria Grécia nesse sentido. Os mais autênticos representantes do ideal grego - em que universalidade e liberdade se conjugam - são em certa medida xénoi em sua própria pátria: como Diógenes; como Sólon, da forma como é apresentado no Cita, "um sábio da terra, mas que viajou muito na Âsia e no Egito (...) e que não está entre os ricos, sendo mesmo pobre" (Cita 5) ; como o próprio Homero que, nas Histórias verdadeiras, se declara um babilônio de nome Tigranes que, tomado como refém (em grego hómeros), adotou como pátria a Grécia (Hist. verd. II, 20). Todos esses exemplos, explorados em razão das intenções que movem Luciano, apontam seguramente para aspectos de sua própria condição de aculturado que deixou, como os citas Tóxaris e Anárcasis, sua pátria, família e bens "por amor da Grécia" (Cita 4). Segundo essa intenção é que se constrói a prática literária de Luciano, uma retórica da alteridade, sem dúvida, não da perspectiva do outro que vê o grego nem do grego que se espelha no outro, mas, mais propriamente, uma retórica do aculturado, do que não é nem mais bárbaro nem enfim grego, um ser híbrido, cujo caráter Luciano reconhece em sua própria produção, através de metáforas diversas, mas sobretudo através da figura do hipocentauro:

"ele me arrancou a máscara trágica e respeitável" - investe o Diálogo personificado referindo-se a Luciano - "e me impôs outra, uma máscara cômica, satírica e quase ridícula (...) Não sofri assim terrível ultraje, eu que, em vez de preservar meu próprio papel, represento o de um comediante e bufão? O que me revolta mais é a absurda mistura de que sou composto. Pois não ando a pé nem sigo a cavalo, como diz o ditado, mas, semelhante a um hipocentauro, tenho o aspecto, para os que me escutam, de um espectro bizarro feito de elementos diferentes (Dupla acusação 33).

São pois os elementos diferentes, a mistura monstruosa de gêneros e funções, o aspecto bizarro e a impossibilidade de classificação que são objeto da acusação contra Luciano. Ele tem consciência disso, mas justifica que não tirou do Diálogo "suas vestimentas gregas para revesti-lo de vestimentas bárbaras, ainda que 
passe eu mesmo por bárbaro" (Dupla ac. 34). Assim, a questão posta pelo Diálogo de um ponto de vista meramente literário é transposta para uma esfera mais ampla, concernente às relações entre gregos e bárbaros. O diferente, o misto, o monstruoso não se opõe simplesmente ao grego — não é tão somente seu outro mas é um aspecto da grecidade mesma.

Nesse contexto ambivalente cria-se espaço para o riso e para a crítica, pois o completamente outro não teria os canais para entender-se e comunicar-se com a esfera do próprio, e o completamente próprio não teria a isenção que a distância fornece para rir de seus próprios valores. Acima das classificações de pátria, família, fortuna e poder, os que privaram do autêntico convívio das musas se encontram. Há uma Grécia idealizada em que se realiza a utopia onde todos são outros e, por essa mesma razão, todos têm idêntico direito sobre o que é próprio. Essa utopia onde todos são xénoi acaba sendo a de todos os que, ainda hoje, se ocupam desse tempo e desse espaço que tratamos como a Antiguidade, o qual, completo e fechado no que lhe é próprio, justamente por isso se abre mais à ação do discurso do outro, exercício que, em sentido mais ou menos genérico, poderia ser identificado com a dinâmica sobre a qual se conformou nossa própria história como cultura: se todos são xénoi com relação à antiga Grécia, todos, em consequiência, têm direito de cidadania. 


\section{BIBLIOGRAFIA}

BALDWIN, B. Studies in Lucian. Toronto, Hakkert, 1973.

BANDINELLI, R. B. Luciano di Samosata e il problema della cultura. In: Dal diario di un borghese. Roma, Riuniti, 1976 : 193-223.

BOMPAIRE, M. J. Lucien écrivain. Imitation et création. Paris, Boccard, 1958.

CASTER, M. Lucien et la pensée religieuse de son temps. Paris, Belles Lettres, 1938.

CROISET, Essai sur la vie et les oeuvres de Lucien. Paris, 1882.

FESTUGIERE, A.-J. La vie spirituelle en Grèce à l'époque hellénistique ou les besoins de l'esprit dans un monde raffiné. Paris, Picard, 1977.

GRONINGEN, B. A. van. General Literary Tendencies in the Second Century A. D. Mnemosyne, 18:41-56, 1965 .

HARTOG, F. Le miroir d'Hérodote: essai sur la représentation de l'autre. Paris, Gallimard, 1980.

HELM, R. Lukian und Menipp. Leipzig, Teubner, 1906.

KORUS, K. The Theory of Humour in Lucian of Samosata. Eos 72:295-313, 1984.

LAIN ENTRALGO, P. Teoria y realidad del otro. Madrid, Alianza, 1983.

LUCIANO. Lucian with an English Translation by A. M. Harmon, K. Kilburn \& M. D. MacLeod. Cambridge, Harvard, 1953-1979 (6 volumes; texto gregoinglês ).

MCCARTHY, B.P. Lucian and Menippus. Yale Classical Studies 4:3-55, 1934.

VERNANT, J.-P. A morte nos olhos. Rio de Janeiro, Zahar, 1988. 